Supporting Information

\title{
Mechano-actuated light-responsive main-chain liquid crystal elastomers
}

Eun-hye Cho, Khuong Luu, and Soo-Young Park*

School of Applied Chemical Engineering, Polymeric Nano Materials Laboratory, Kyungpook National University, Daegu 41566, Republic of Korea.

E-mail: psy@knu.ac.kr 


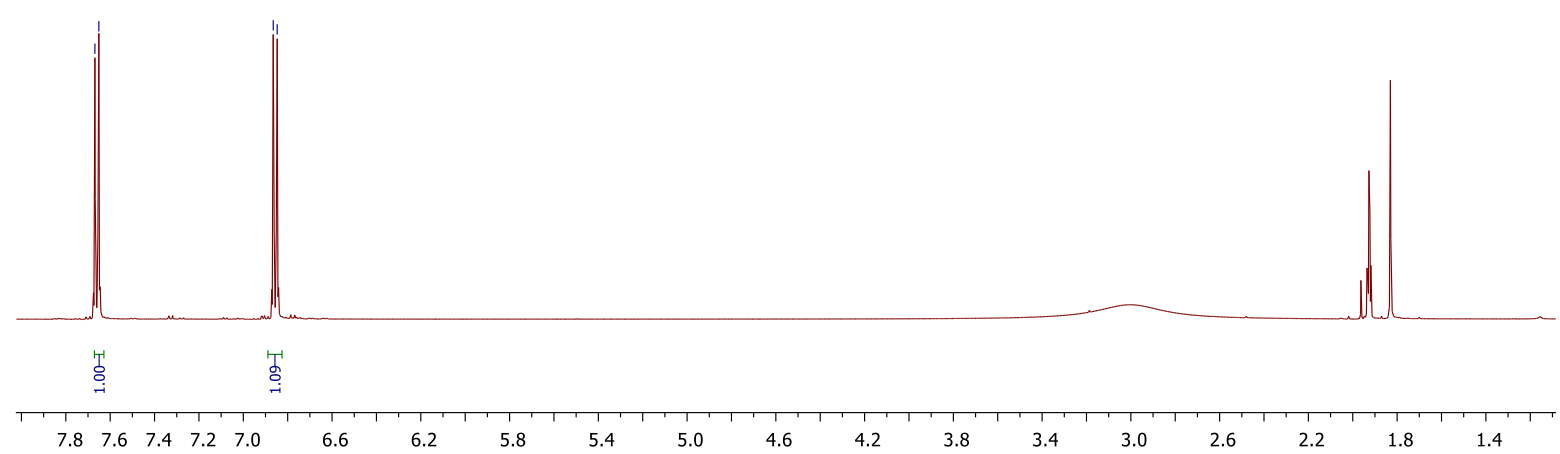

Figure S1. ${ }^{1} \mathrm{H}$ NMR of pre-D6OA (500 MHz, acetone-d6, ppm): $\delta 6.86(\mathrm{~d}, \mathrm{~J}=10 \mathrm{MHz}, 4 \mathrm{H}, \mathrm{Ar})$ and $\delta 7.66(\mathrm{~d}, \mathrm{~J}=10$ $\mathrm{MHz}, 1 \mathrm{H}, \mathrm{Ar})$.

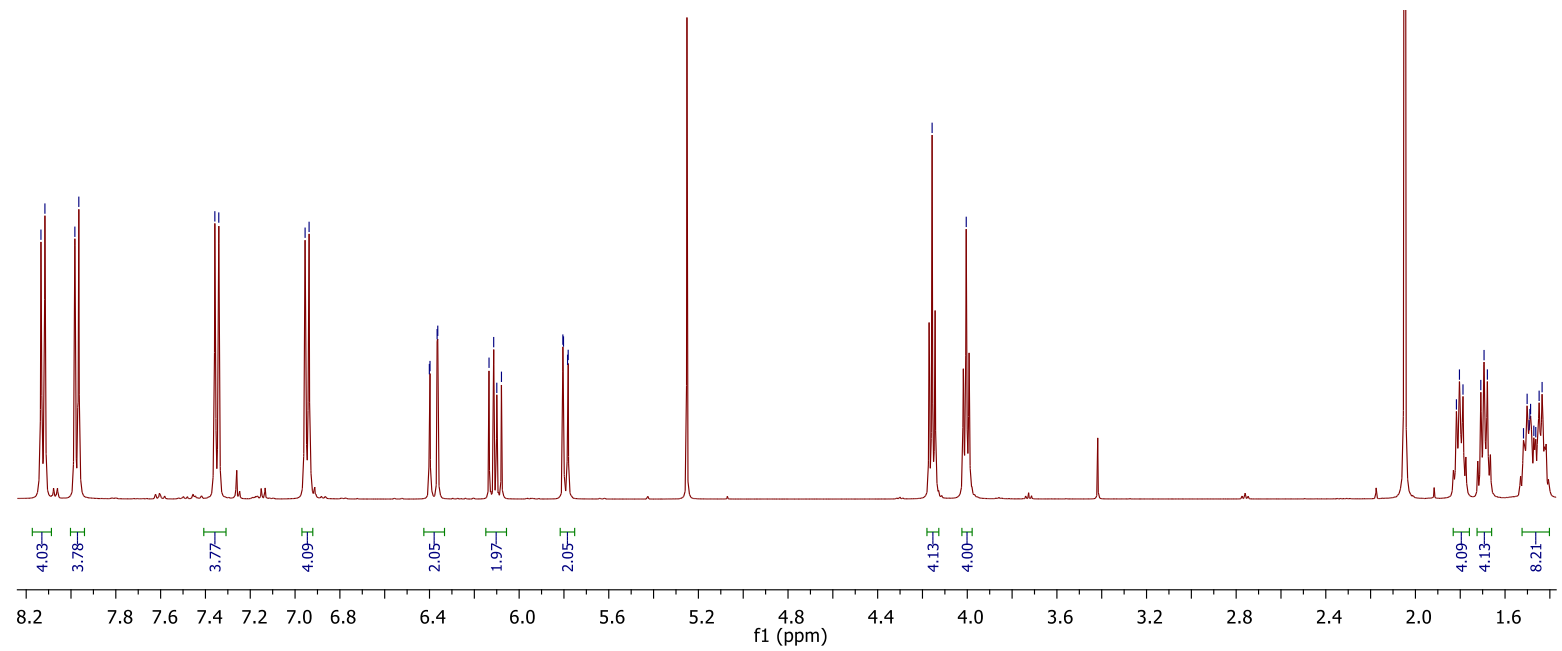

Figure S2. ${ }^{1} \mathrm{H}$ NMR of D6OA $\left(500 \mathrm{MHz}, \mathrm{CDCl}_{3}, \mathrm{ppm}\right): \delta 1.43-1.8\left(\mathrm{~m}, 16 \mathrm{H}, \mathrm{CH}_{2}\right), \delta 4.00(\mathrm{t}, \mathrm{J}=5 \mathrm{MHz}, 4 \mathrm{H}$, $\left.\mathrm{COOCH}_{2}\right), \delta 4.16\left(\mathrm{t}, \mathrm{J}=5 \mathrm{MHz}, 4 \mathrm{H}, \mathrm{OCH}_{2}\right), \delta 5.80\left(\mathrm{~d}, \mathrm{~J}=10 \mathrm{MHz}, 2 \mathrm{H},=\mathrm{CH}_{2}\right), \delta 6.10(\mathrm{dd}, \mathrm{J}=10 \mathrm{MHz}, 2 \mathrm{H},=\mathrm{CH}), \delta$ $6.37\left(\mathrm{~d}, \mathrm{~J}=15 \mathrm{MHz}, 2 \mathrm{H},=\mathrm{CH}_{2}\right), \delta 6.95(\mathrm{~d}, \mathrm{~J}=10 \mathrm{MHz}, 4 \mathrm{H}, \mathrm{Ar}), \delta 7.35(\mathrm{~d}, \mathrm{~J}=10 \mathrm{MHz}, 4 \mathrm{H}, \mathrm{Ar}), \delta 7.97(\mathrm{~d}, \mathrm{~J}=5 \mathrm{MHz}$, $4 \mathrm{H}, \mathrm{Ar})$, and $\delta 8.12(\mathrm{~d}, \mathrm{~J}=5 \mathrm{MHz}, 4 \mathrm{H}, \mathrm{Ar})$. 


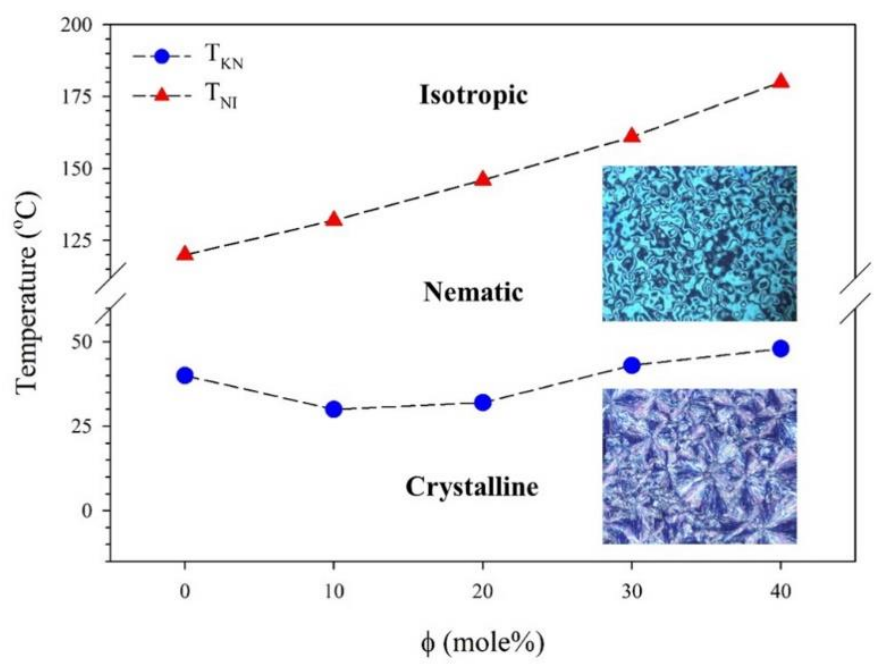

Figure S3. Phase diagram of the RM82/D6OA mixtures as a function of $\phi$ (D6OA mole\%) from DSC thermograms during the cooling experiments. $\mathrm{T}_{\mathrm{KN}}$ and $\mathrm{T}_{\mathrm{NI}}$ represent the crystal-to-nematic and nematic-to-isotropic temperatures, respectively. Inset figures are the polarized optical microscope (POM) images of each phase.
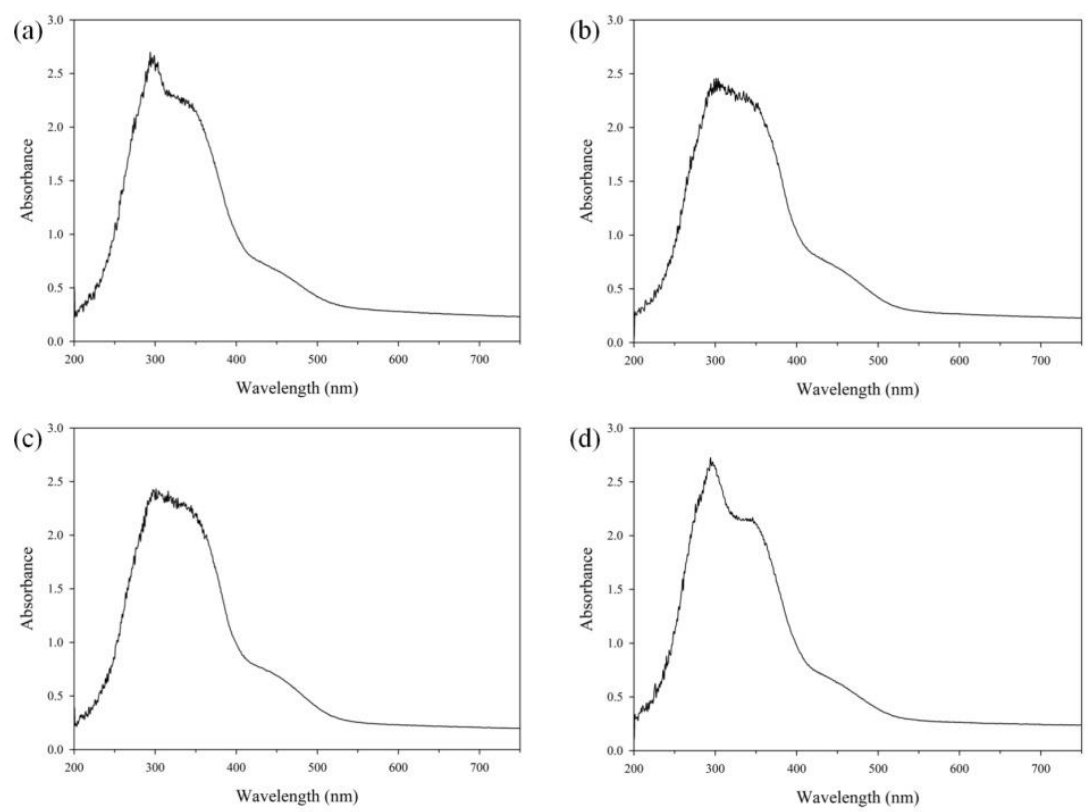

Figure S4. UV-vis spectra of (a, b) the M azo-LCE film (a) before and (b) after UV irradiation at $100 \mathrm{~mW} \mathrm{~cm}^{-2}$ for $1 \mathrm{~min}$, (c) UV-shed M azo-LCE film at $500 \mathrm{~mW} \mathrm{~cm}^{-2}$ for $2 \mathrm{~h}$ after visible-light irradiation, and (d) UV-shed $\mathrm{M}$ azo-LCE film after mechanical drawing to the original length 

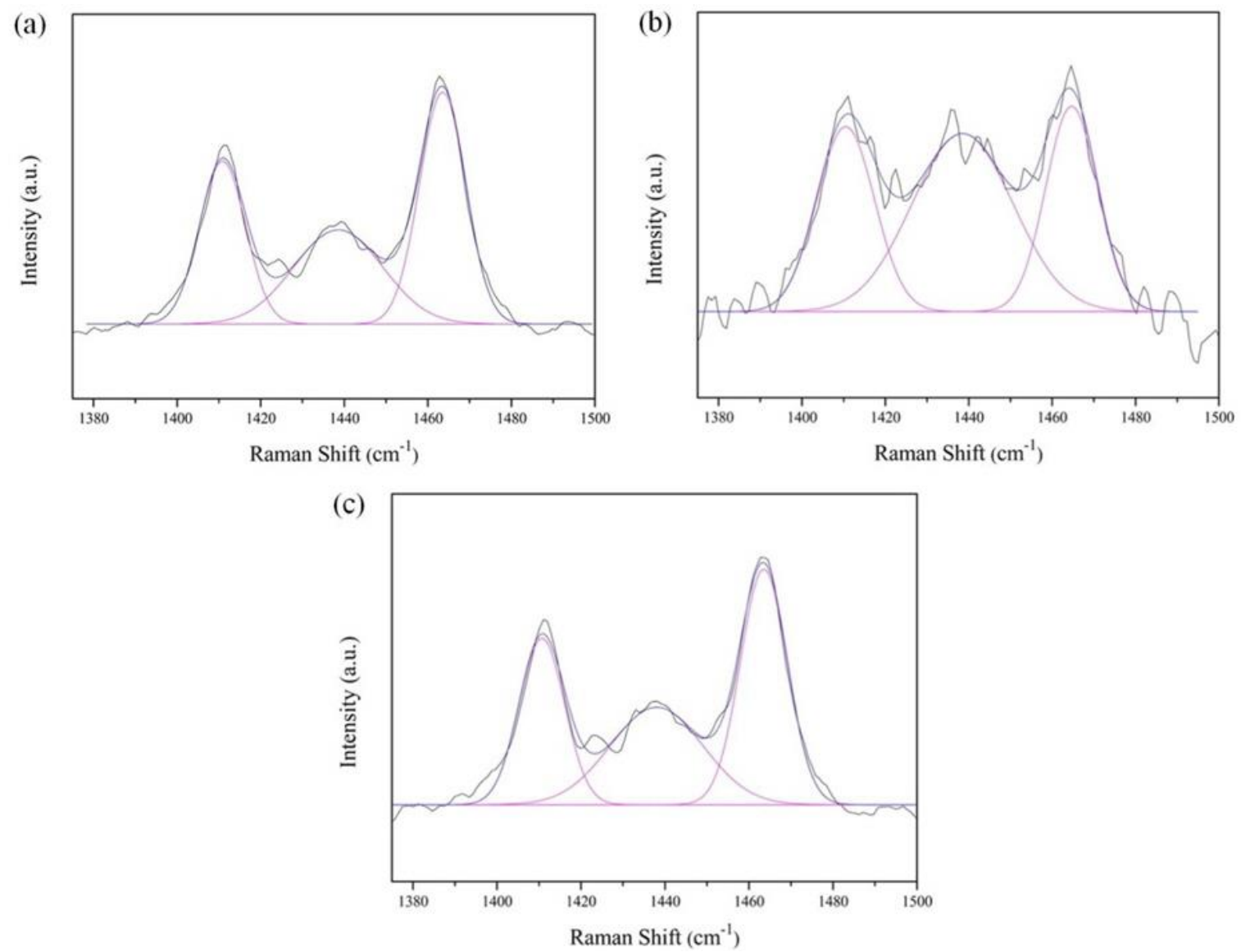

Figure S5. Curve separation of the C1, C2, and C3 bands of Raman spectra (Figure 4d) of the M azo-LCE film (a) before and (b) after exposure to UV $\left(365 \mathrm{~nm}, 100 \mathrm{~mW} \mathrm{~cm}{ }^{-2}\right)$ for $1 \mathrm{~min}$ and (c) after stretching the UV-shed (contracted) film to its original length.

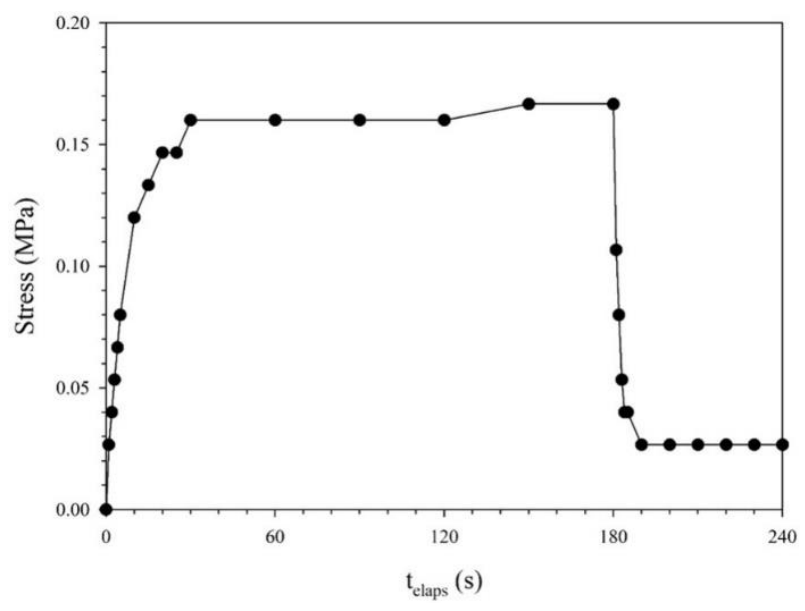

Figure S6. Stress on the M azo-LCE film $(\phi=20 \mathrm{~mol} \%, 3 \mathrm{~mm}$ (width) $\times 15 \mathrm{~mm}$ (length) $\times 25 \mu \mathrm{m}$ (thickness) $)$ as a function of time ( $\left.\mathrm{t}_{\text {elaps }}\right)$ at a constant length of $15 \mathrm{~mm}$ during UV light irradiation $\left(365 \mathrm{~nm}, 100 \mathrm{~mW} \mathrm{~cm}^{-2}\right)$ for $180 \mathrm{~s}$ and after turning off UV. 

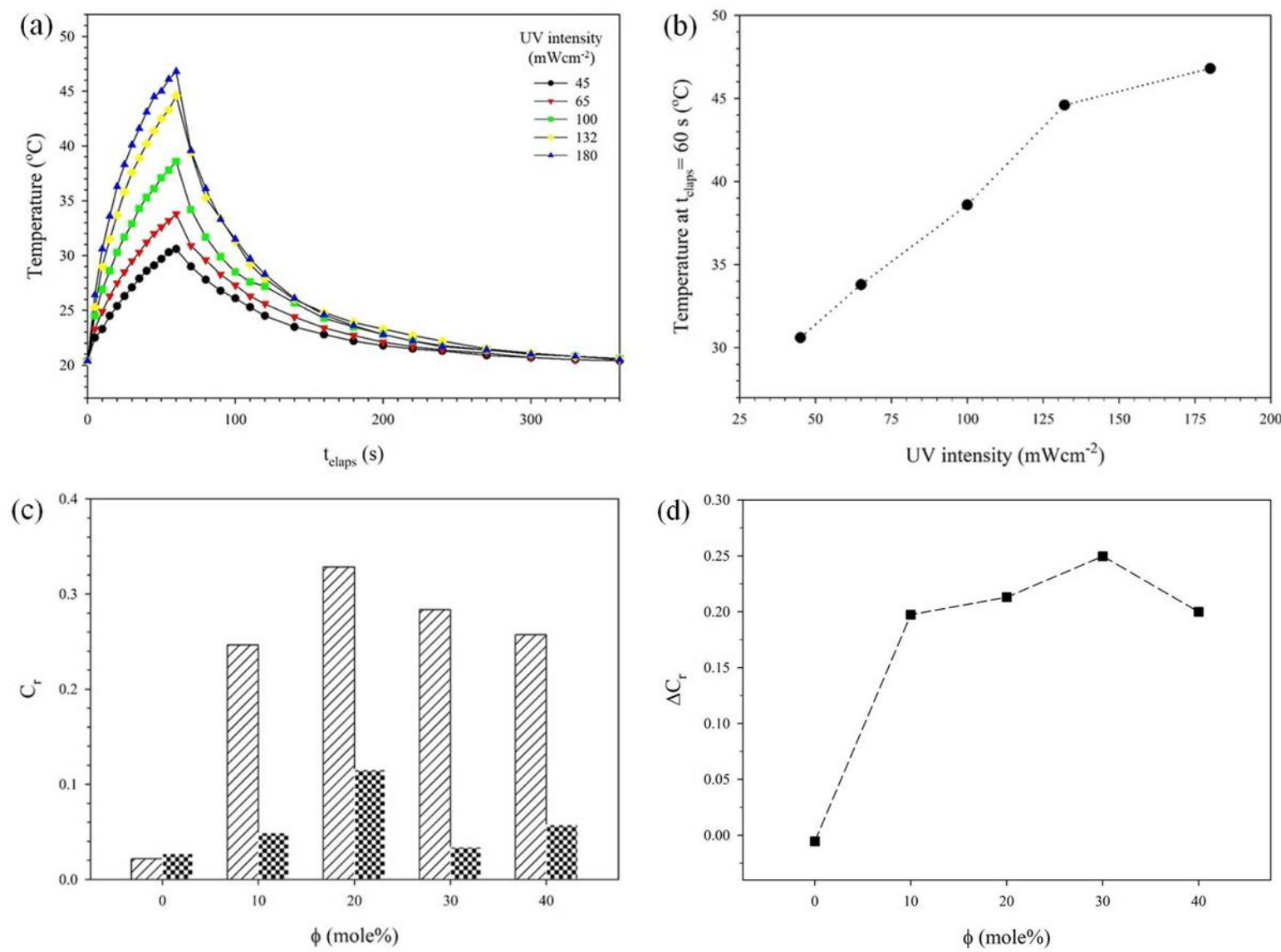

Figure S7. (a) Temperature of the M azo-LCE film as a function of the elapsed time ( $\left.t_{\text {elaps }}\right)$ during UV irradiation at intensities of $45,65,100,132$, and $180 \mathrm{~mW} \mathrm{~cm}^{-2}$ for $60 \mathrm{~s}$ and after the UV machine is turned off at telaps $=60 \mathrm{~s}$, (b) the temperature at $t_{\text {elaps }}=60 \mathrm{~s}$ as a function of UV intensity, and (c) the $\mathrm{C}_{\mathrm{r}} \mathrm{s}$ of M azo-LCE films as a function of $\phi$ after (dash rod) UV irradiation $\left(100 \mathrm{~mW} \mathrm{~cm}^{-2}\right.$ for $\left.\mathrm{t}_{\mathrm{UV}}=60 \mathrm{~s}\right)$ and (checker rod) heating at $38{ }^{\circ} \mathrm{C}$ without $\mathrm{UV}$ irradiation and (d) the $\Delta \mathrm{C}_{\mathrm{r}}$ between (c, i) and (c, ii) as a function of $\phi$.

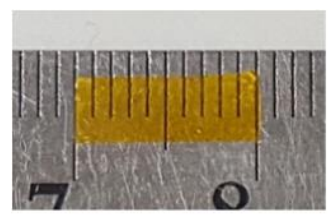

(a)

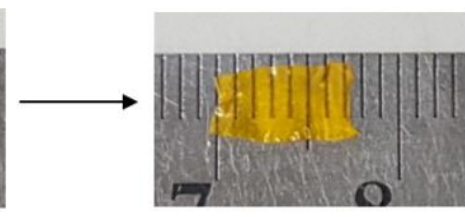

(b)

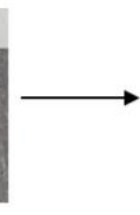

(c)

Figure 8. Photographic images of the M azo-LCE film: (a) initial, (b) UV-shed, and (c) after storing in an oven at $80^{\circ} \mathrm{C}$ for $1 \mathrm{~h}$. 

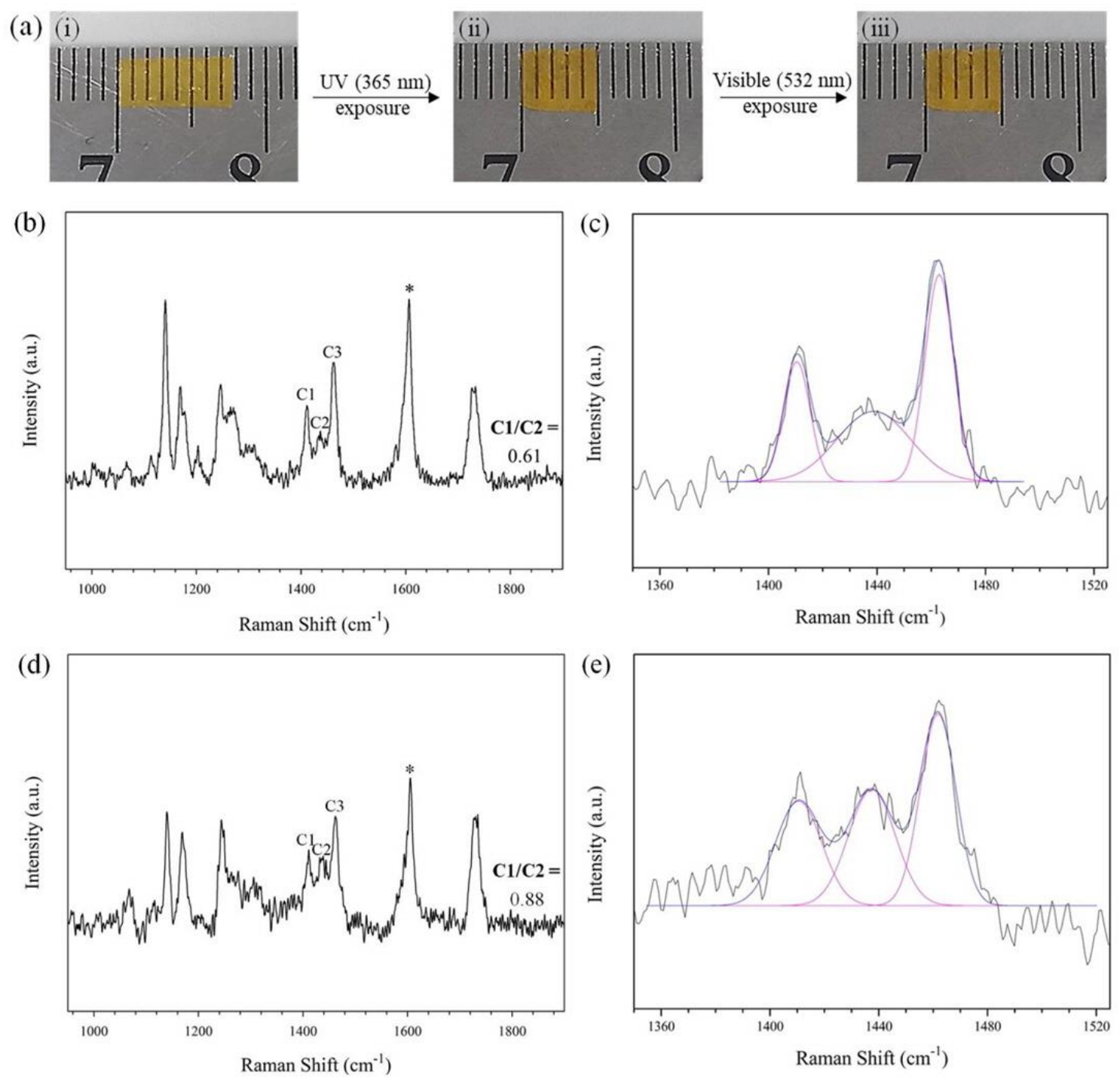

(f)
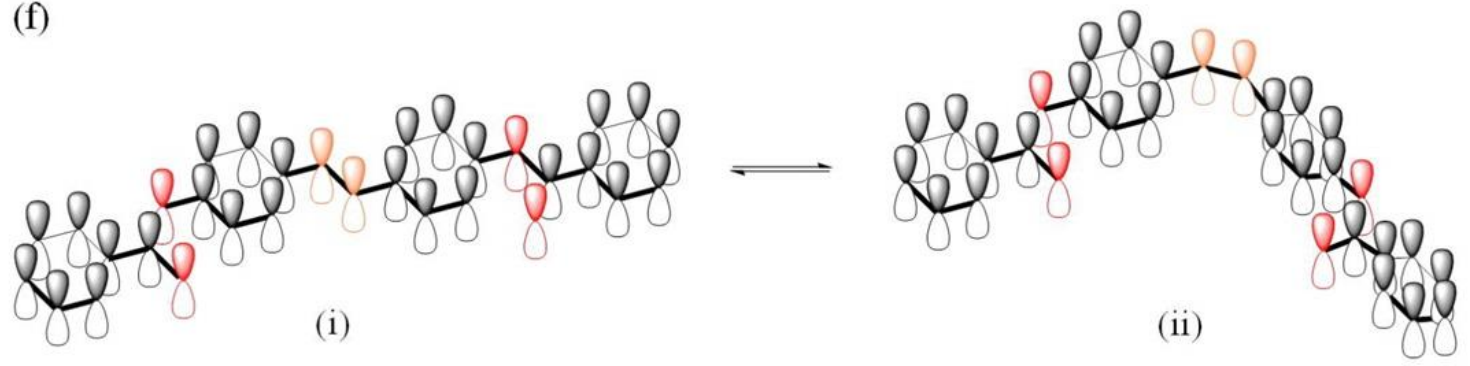

Figure S9. (a) Photographic images of the flattened M azo-LCE film (i) before and (ii) after UV irradiation (365 nm, $100 \mathrm{~mW} \mathrm{~cm}^{-2}$ ) for $1 \mathrm{~min}$ and (iii) after visible-light exposure $\left(532 \mathrm{~nm}, 500 \mathrm{~mW} \mathrm{~cm}^{-2}\right.$ ) for $2 \mathrm{~h}$; (b) normalized Raman spectrum of the UV-shed (contracted) M azo-LCE film after visible-light exposure; (c) curve separation of the C1, C2, and $\mathrm{C} 3$ bands of (b); (d) normalized Raman spectra (excited at $785 \mathrm{~nm}$ ) of the M azo-LCE film after the $10^{\text {th }}$ drawing in Figure 6a; (e) curve separation of the C1, C2, and C3 bands of (d); The normalization in (b) and (d) was performed with the peak at $1607 \mathrm{~cm}^{-1}$ marked with an asterisk. 
(a)

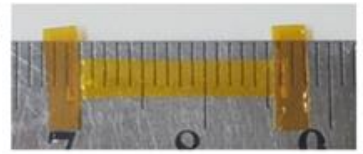

UV exposure for $1 \mathrm{~min}$ (b)

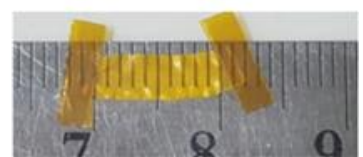

(d)

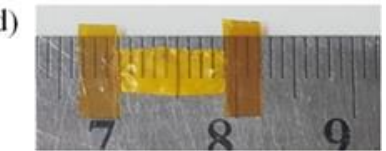

Figure S10. Photographic images of the M azo-LCE film redrawn $(a, b)$ under day light and (c, d) in dark room (a, c) before and $(b, d)$ after UV irradiation.

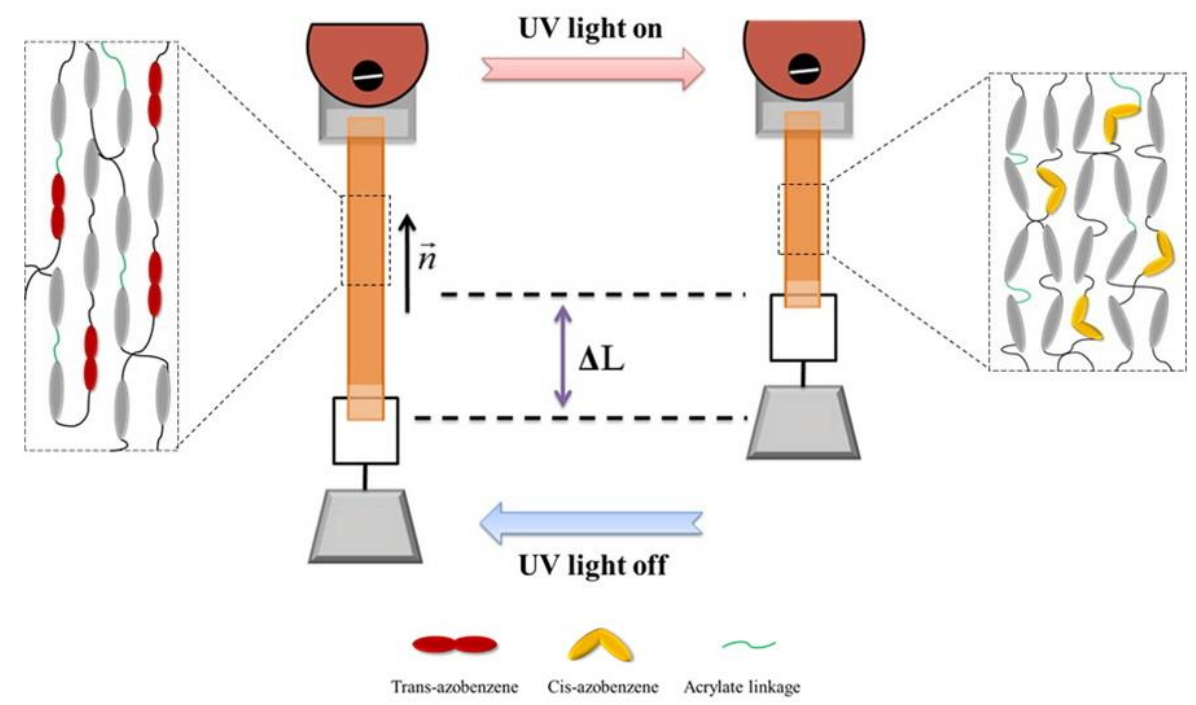

Figure S11. Schematic of the actuation of the M azo-LCE film with a hangered weight during UV irradiation and turning off UV; the sample dimensions were $9.5 \mathrm{~mm}$ (length) $\times 3.0 \mathrm{~mm}$ (width) $\times 0.025 \mathrm{~mm}$ (thickness). 

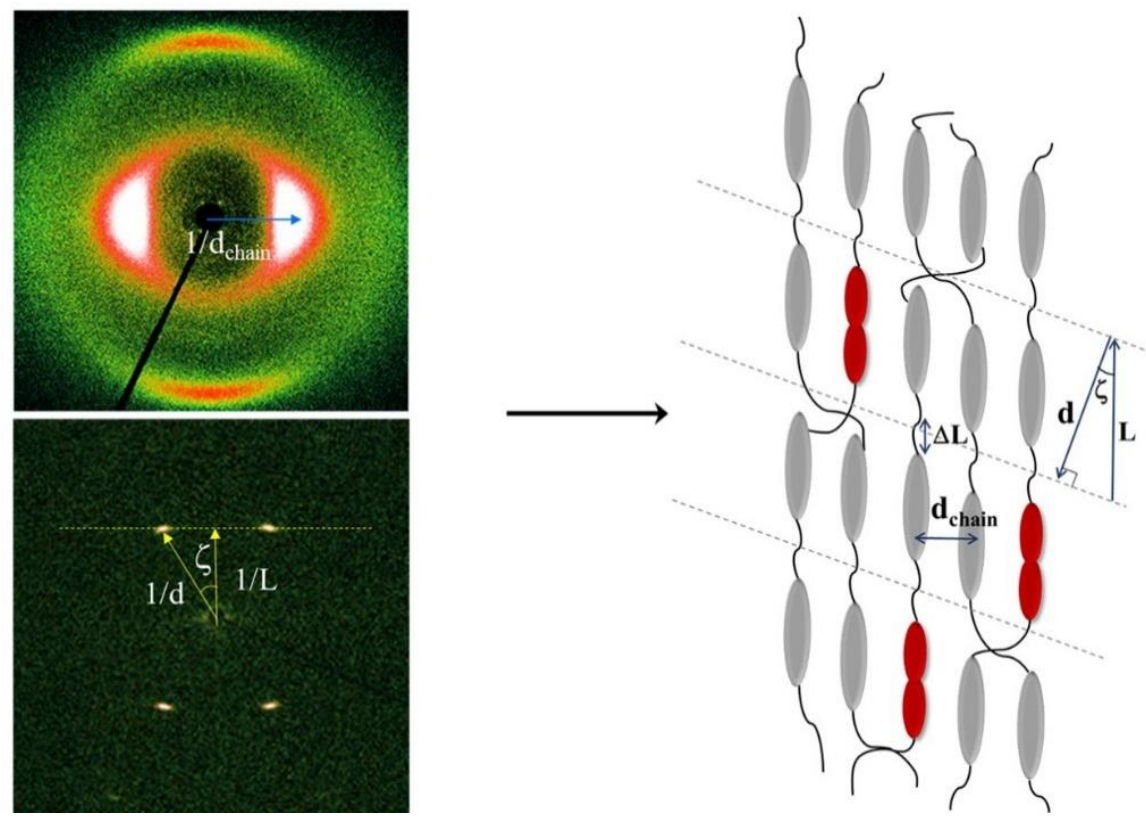

Figure S12. Analysis of the chain repeat distance (L) and staggering distance $(\Delta \mathrm{L})$ based on the interchain distance $\left(\mathrm{d}_{\text {chain }}\right)$ from the WAXS pattern as well as the d-spacing $(\mathrm{d})$ and tilting angle $(\zeta)$ from the SAXS pattern; dotted lines represent layers.
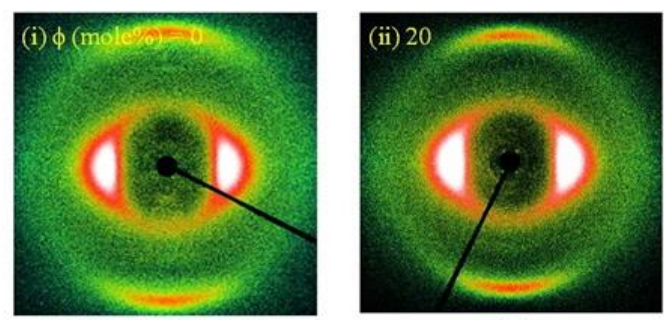

(a)
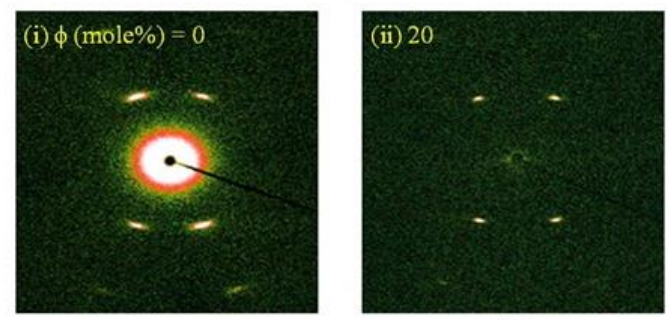

(b) (c)

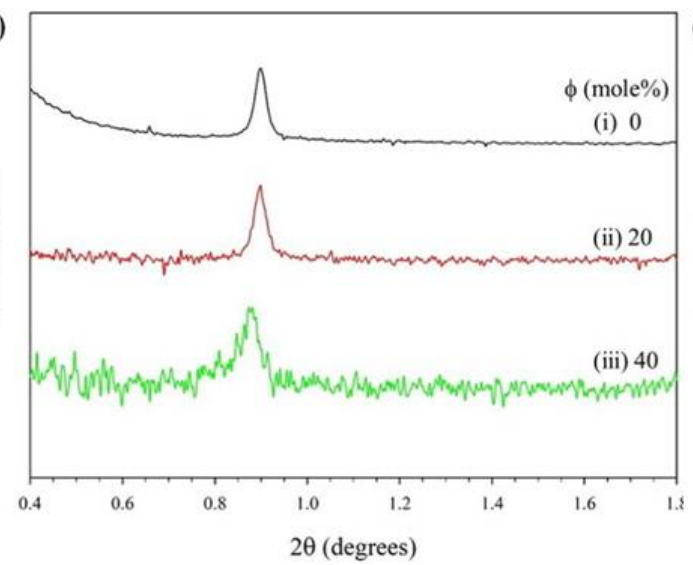

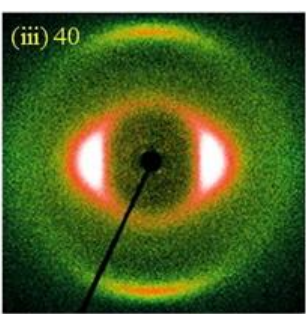

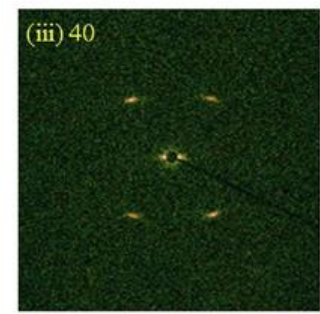

(d)

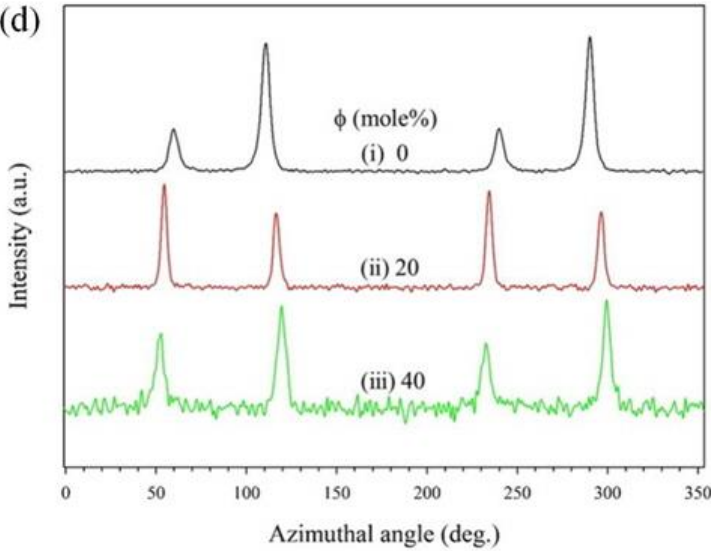


Figure S13. (a) WAXS and (b) SAXS patterns, (c) azimuthally averaged q scans, and (d) azimuthal scans at $q=1.48$ $\mathrm{nm}^{-1}$ of the M azo-LCE films prepared at $\phi$ values of (i) 0, (ii) 20, and (iii) $40 \mathrm{~mol} \%$.
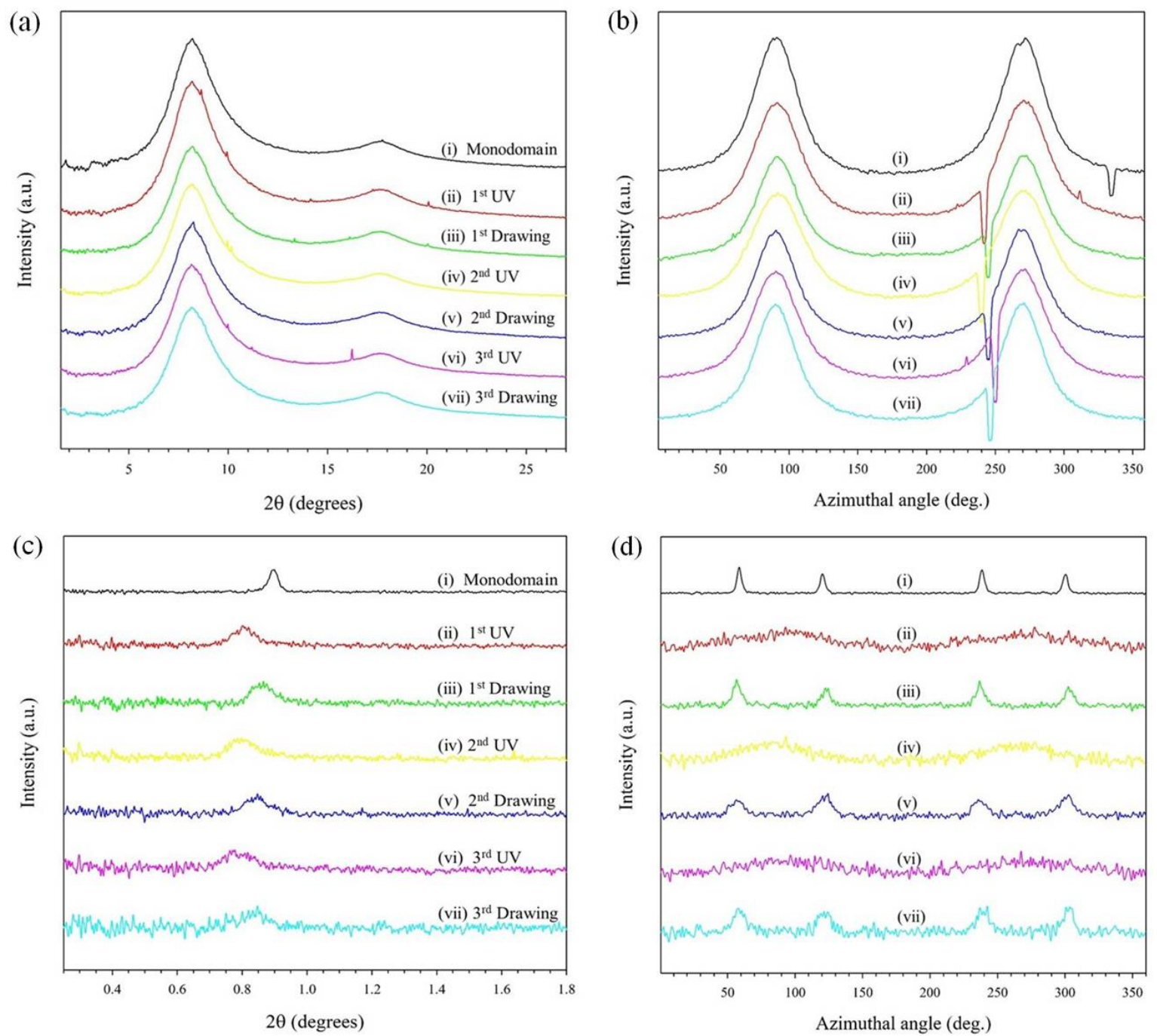

Figure S14. (a, c) Azimuthally averaged q scans and (b, d) azimuthal scans at $\mathrm{q}=\sim 14.34$ and $\sim 1.48 \mathrm{~nm}^{-1}$ of the (a, b) WAXS and (c, d) SAXS patterns of the M azo-LCE film during alternating UV irradiation and mechanical drawing for three cycles. The M azo-LCE films were drawn at $D_{\mathrm{r}}=1.33$ and subjected to UV irradiation at $100 \mathrm{~mW} \mathrm{~cm}^{-2}$ for $150 \mathrm{~s}$. The discontinuity lines in (b) can be attributed to the beam stopper. 
Table S1. Chain repeat distance $(\mathrm{L})$, interchain distance $\left(\mathrm{d}_{\text {chain }}\right)$, tilting angle $(\zeta)$, and full width at half maximum of the azimuthal peak $(\Delta \zeta)$, d-spacing $(\mathrm{d})$, and staggering distance $(\Delta \mathrm{L})$ of the M azo-LCE films during alternating UV irradiation and mechanical drawing for cycles. The M azo-LCE films were drawn at $\mathrm{D}_{\mathrm{r}}=133 \%$ with UV irradiation at $100 \mathrm{~mW} \mathrm{~cm}^{-2}$ for $150 \mathrm{~s}$

\begin{tabular}{ccccccc}
\hline Sample & $\begin{array}{c}\mathrm{d} \\
(\mathrm{nm})\end{array}$ & $\begin{array}{c}\zeta \\
(\text { degree })\end{array}$ & $\begin{array}{c}\mathrm{L} \\
(\mathrm{nm})\end{array}$ & $\begin{array}{c}\Delta \mathrm{L} \\
(\mathrm{nm})\end{array}$ & $\begin{array}{c}\Delta \zeta \\
(\text { degree })\end{array}$ & $\begin{array}{c}\mathrm{d}_{\text {chain }} \\
(\mathrm{nm})\end{array}$ \\
\hline Polydomain & 4.00 & & & & & \\
Monodomain & 4.00 & 31.0 & 4.67 & 1.24 & 4.11 & 0.4380 \\
\hline $1^{\text {st }} \mathrm{UV}$ & 4.43 & 3.77 & 4.44 & 0.02 & 68.99 & 0.4393 \\
$1^{\text {st }}$ Drawing & 4.20 & 33.12 & 5.01 & 1.50 & 5.86 & 0.4380 \\
\hline $2^{\text {nd }} \mathrm{UV}$ & 4.46 & 10.95 & 4.54 & 0.16 & 59.92 & 0.4393 \\
$2^{\text {nd }}$ Drawing & 4.37 & 32.20 & 5.16 & 1.47 & 7.98 & 0.4368 \\
\hline $3^{\text {rd }} \mathrm{UV}$ & 4.53 & 16.63 & 4.54 & 0.02 & 51.60 & 0.4393 \\
$3^{\text {rd }}$ Drawing & 4.27 & 31.93 & 5.03 & 1.41 & 7.60 & 0.4380 \\
\hline
\end{tabular}

Movie S1. Movie of the M azo-LCE film during alternating UV irradiation $\left(C_{r}=0.34\right)$ and mechanical drawing $\left(C_{r}=\right.$ $0)$.

Movie S2. Movie of the M azo-LCE film under stress $(\sigma)$ applied by hanging different weights during UV irradiation at $100 \mathrm{~mW} \mathrm{~cm}^{-2}$ for $60 \mathrm{~s}$ and after the turning off UV. 